\title{
Pemanfaatan Sampah Jaring Ikan yang Rusak sebagai Alternatif Pengganti Busa dan Dakron
}

\author{
Muazaroh Nur Azizah
}

NIM: MD218051, J urusan Fisika, Fakult as Mat emat ika dan Ilmu penget ahuan Alam Universit as Sebelas Maret Surakart a, Jl. Ir .Sutami 36 A Kentingan Surakart a 57126 Telp/ Fax.(0271) 669017

\section{Pendahuluan}

Indonesia termasuk negara yang kaya akan kekayaan laut nya. Kekayaan yang diperoleh sangat melimpah, terut ama kekayaan laut nya. Laut an di Indonesia sekit ar dua pert iga dari luas Indonesia. Sehingga Indonesia disebut sebagai negara marit im Sehingga tidak mengherankan apabila mayorit as j umlah penduduk di Indonesia bermat a pencaharian yang berkait an dengan laut khususnya , air pada umumnya. Banyak manf aat yang diperoleh dari laut baik di bawah permukaan laut maupun diat as permukaan laut. Mata pencaharian yang erat kait annya adalah nelayan. Dengan adanya nelayan kebut uhan akan prot ein pada manusia menj adi terpenuhi. J enis ikan, maupun yang lain.

Namun ada beberapa masalah, diant aranya adalah penangkapan ikan yang berlebihan, perubahan iklim dan sampah (Marzuki, Sugito, \& At maj a, 2018). Para nelayan biasanya menggunakan j aring berbahan nilon unt uk menangkap ikan. Sedangkan nilon merupakan daint ara jenis plast ik. Plast ik menj adi salah sat u bahan yang banyak dimanf aat kan dalamberbagai peralat an baik it $u$ peralat an rumah tangga , ot omat if, dan lain- lain. Bahan plast ik digunakan karena kuat dan tidak mudah rusak dan pelapukan (Sahwan, Mart ono, Wăhyono, \& Wisoyodharm, 2005).

Meskipun plast ik memiliki banyak kelebihan, plast ik j uga berdampak buruk terhadap lingkungan. Plastik sangat berpot ensi mencemari lingkungan karena merupakan bahan yang sulit terdegradasi yang mana apabila dit imbun dalam panimbunan akhir akan menimbulkan berbagai masalah diant aranya, (1) sampah plast ik akan menempat i bagian yang seharusnya sampah lain dapat menggunakannya, (2) sifat ringan dari plastik, plast ik yang dit imbun at au 
dit ut up dengan tanah akan cenderung terangkat ke permukaan dan menyebabkan lingkungan sekit ar kot or, dan (3) jika plast ik dibakar at au terbakar akan menimbulkan zat-zat berbahaya unt uk kesehat an . sement ara , apabila tercecer di badan air, plastik cenderung menyumbat aliran (Sahwan, Mart ono, Wahyono, \& Wisoyodharmo, 2005).

Penggunaan j aring ikan ternyat a menj adikan masalah baru bagi ekosistem laut. Para nelayan biasanya akan memperbaiki j aring bilamana jaringnya hanya mengalami sedikit kerusakan, akan tet api jika tidak memungkinkan unt uk diperbaiki, mereka tidak akan menggunakannya lagi. Seringkali nelayan langsung membuangnya kelaut (Mainnah, Diniah, \& Iskandar, 2016). Sehingga j aring tersebut menj adi sampah at au limbah anorganik. Hal yang dilakukan para nelayan selanj ut nya bervariasi, diant aranya adalah menjualnya at au membuangnya. Mereka membuang dit empat sampah at aupun membiarkannya berserakan disekit ar pantai. Cara membuang inilah yang cenderung menambah masalah bagi lingkungan hidup baik it $u$ darat maupun laut.

Membuang j aring ikan yang rusak disekit ar pant ai dapat membuat lingkungan pant ai at au pesisir laut menj adi kot or . Penimbunan jaring dengan tanah berpot ensi akan terangkat ke permukaan tanah, sehingga kurang nyaman dipandang mata. Selain it $u$, jaring ikan yang berbahan dasar nilon at au yang sej enisnya akan sangat sulit terurai, but uh wakt u yang sangat lama unt uk menguraikannya. Hal ini j uga dapat berdampak pada tersumbat nya aliran air at aupun ketika terseret pasang surut air laut maupun ombak, maka j aring tersebut akan berpindah tempat di air sehingga menj adikan biot a- biot a di dalammaupun sekit ar laut terperangkapj aring yang beruj ung pada kematian makhluk hidup it u sendiri.

Jaring ikan yang dibakar, terlihat dapat mengurangi jumlah limbah tersebut, akan tet api pembakaran jaring ikan j ust ru dapat menimbulkan polusi udara dan akan menimbulkan zat- zat berbahaya dari hasil pembakarannya, merusak tanah yang dalamj angka panj ang beruj ung dengan pencemaran tanah.

\section{Data dan informasi yang mendukung}


Perbedaan lama wakt u t erurainya sampah berdasarkan bahan dasar pembuat annya, menurut WHOseperti pada tabel.

Berikut t abel sampah berdasarkan t erurainya (Marzuki, Sugit o, \& At maj a, 2018).

\begin{tabular}{|l|l|}
\hline Kat egori sampah & Terurai dalam \\
\hline Kart on/ kert as & $2,5-5$ bulan \\
\hline Filt er rokok & $10-12$ tahun \\
\hline Plast ik semua j enis & $50-200$ tahun \\
\hline Kant ong plastik & $10-12$ tahun \\
\hline $\begin{array}{l}\text { Bahan kulit dan } \\
\text { karet }\end{array}$ & $25-40$ tahun \\
\hline
\end{tabular}

\begin{tabular}{|l|l|}
\hline nilon & $30-40$ tahun \\
\hline st erofom & Tidak hancur \\
\hline Alumuniumdan besi & Tidak hancur \\
\hline kaca & Tidak hancur \\
\hline Kayu olahan & 2-6 tahun \\
\hline Pempers & $10-12$ tahun \\
\hline
\end{tabular}

\section{Tuj uan dan Manfaat}

Tuj uan dari penulisan ini adalah memberikan gagasan solusi at as adanya sampah berupa jaring ikan yang tidak layak pakai sebagai media pengganti busa dan dakron pada peralat an rumah t angga. Penggunaan limbah j aring ini bisa diaplikasikan dalamkursi sof a, bant al \& guling, kasur, juga pada boneka.

Manf aat yang diperoleh dari solusi ini adalah dapat mengurangi produksi busa, dakron maupun kapas sint et is pada indust ri tekstil. Mengurangi sampahsampah pada laut khususnya, berupa jaring ikan nilon menj adi tambahan pendapat an . ikut sert a menj aga kelest arian lingkungan hidup terut ama laut dan pant ai dan menj aga keindahannya.

\section{Gagasan}

\section{Kondini terkini pencetus}

Pada saat artikel ini dit ulis, diket ahui bahwa terj adi fenomena limbah 
j aring ikan yang banyak tanpa adanya pemanfaat an sehingga menimbulkan masalah baru baru dalamekosist emlaut khususnya. Diant aranya adalah sampah jaring ikan yang dibuang nelayan, yang mana bersif at tidak dapat tergradasi oleh mikroorganisme (Mainnah, Diniah, \& Iskandar, 2016).

\section{Solusi yang pernah diterapkan}

Solusi yang pernah digunakan unt uk mengat asi permasalahan ini diant aranya adalah memproduksi j aring ikan berbahan dasar serat alami, sebagai inovasi yang bert uj uan mencipt akan serat yang kuat namun mudah terurai. Mereka lebih menekankan pada j enis bahan baku dari serat it u sendiri (Mainnah, Diniah, \& Iskandar, 2016).

Selain dengan mencipt akan bahan serat alami, ada juga yang mengkampanyekan pemanf aat an limbah j aring ikan sebagai alt ernatif jaring net Voli. FIVB at au Federasi Bola Voli Dunia bersama kelompok konservasi laut "Ghost Fishing Foundation” berkolaborasi mengumpulkan j aring ikan bekas dan mendaur ulangnya menj adi net bola voli unt uk masyarakat setempat. Proyek tersebut diberi nama "Good Net" diluncurkan di Pant ai Copacabana di Rio de J aneiro, tempat turnamen bola voli pant ai Olimpiade 2016, seperti yang dilansir oleh Reut ers (www.ant aranews.com, Maret 2019). (Suswant o, 2019)

Dalamhal tat a busana, ada salah seorang desainer yang merancangnya menj adi busana daur ulang berbahan dasar limbah j aring ikan (wuw.Liput an6. com, April 2018) (Wulan, 2018).

Selain it u dit emukan j uga, pemanf aat an limbah j aring ikan sebagai sepatu daur ulang yang tidak kalah saing dari sepatu- sepatu yang telah ada (www.inilahcomJ Juli 2015) (Claresta, 2015).

\section{Kehandalan gagasan}

Dari segi j umlah, ket ersediaan limbah j aring ikan yang cukup banyak di Indonesia menj adi kemudahan bagi masyarakat unt uk memanf aat kannya. J aring ikan banyak digunakan para nelayan baik di laut maupun di sungaisungai besar melimpah sert a menyebar karena di wilayah Indonesia yang 
sebagian besar berupa perairan ini dapat dimanf aatkan oleh masyarakat Indonesia secara luas , yang daerahnya dekat dengan perairan (daerah yang mayorit as bermat a pencaharian menangkap ikan).

Dari segi ekonomi , dengan adanya pemanf aat an limbah j aring ikan ini dapat membuka peluang usaha bagi indust ri rumah t angga. J aring ikan limbah tersebut secara tidak langsung akan diperjual- belikan oleh pihak nelayan dengan pihak pengraj in indust ri rumah tangga akan menambah penghasilan nelayan dari menj ual j aring bekas.

Analisis mengenai aspek yang dimiliki oleh j aring ikan dengan keunggulannya ternyat a dengan keunggulannya , ternyat a pada jaring ikan memiliki hubungan yang menunj ukkan pot ensi j aring ikan unt uk dij adikan alt ernat if pengganti busa, kapas sint et is, at aupun dakron. Dari segi fisik, j aring bisa berubah bent uk sesuai wadahnya. Sehingga mudah diamplikasikan dalambeberapa bent uk seperti bant al, guling, kasur, sofa at aupun boneka. Selain it u permukaan fisiknya yang berongga menj adikan teksur yang tidak pada padat dan mudah saat diaplikasikannya.

\section{Pihak- pihak yang terkait}

Dalampemanf aat an j aring sebagai media penggant i busa dan dakron, hal yang pert ama harus dilakukan adalah mendapat kan j aring ikan sebagai bahan bakunya. Unt uk memperolehnya dapat secara langsung pada nelayan disekit ar laut at au daerah yang masyarakat nya mayorit as bermat a pencaharian sebagai nelayan dengan cara membelinya at au membeli pada tempat jual beli j aring iklan.

Nelayan yang berada disekit ar sungai umumnya lebih sulit unt uk mendapat kan j aring ikan bekas. Karena tidak semua yang tinggal di sekit ar sungai yang besar bermat a pencaharian sebagai nelayan. Mereka ada yang mengadu nasib dengan pekerj aan lain. Sehingga unt uk memperolehnya akan lebih susah. Unt uk mempermudah mendapatkan j aring ini diperlukan pengertian bisa melalui sosialisasi akan arti pent ing menj aga lingkungan dari nelayan it $u$ sendiri supaya tidak dibuang at aupun membakarnya. Perlu adanya dukungan 
pemerint ah sebagai fasilisat or. Melalui dinas perikanan dan kelautan, diharapkan pemerint ah dapat memberi penget ahuan dan pengarahan, memberi penyuluhan, sert a menyediakan fasilit as berupa tempat unt uk menampung limbah- limbah anorganik pada ekosist emlaut.

Dalamproses pemanfaat an limbah j aring ini tidak memerlukan alat-alat yang sulit dan mahal. Proses pencucian dan pengeringan tidak memerlukan alat khusus dan mahal. Disini , peran akt if dari masyarakat dan kreativit as dari masyarakat it u sendiri yang menj adi yang menj adi kunci ut ama dalam mengembangkan gagasan ini menj adi sebuah prakt ek. Agar pemanf aat an limbah j aring ini menj adi lebih luas, perlu adanya peningkat an produksi yang lebih tinggi, baik dalamhal produk dan kualitas.

\section{Strategi penerapan}

Pemanf aat an limbah j aring ikan ini adalah salah sat u cara unt uk mengurangi banyaknya limbah pada lingkungan laut dan pant ai. Terealisasinya gagasan ini diperlukan minat dan kesadaran masyarakat agar turut serta menj aga lingkungan sekit ar, dan memahami arti pent ing adanya gerakan daur ulang. Perlu dilakukan pembukt ian dengan cara pelat ihan langsung, sehingga langsung bisa diket ahui hasilnya.J ika hasilnya sesuai prediksi , maka akan dilakukan tindak lanjut terhadap hasil yang ada.

\section{Tahap pemanf aat an}

Unt uk menggunakan jaring ikan, hanya menempuh beberapa t ahap, yait u pemilihan j aring ikan sesuai dengan j enis bahan, pecucian, pengeringan, dan terakhir pengaplikasian.

Pemilihan jaring ikan sesuai dengan j enis bahan

J aring yang digunakan dikelompokkan berdasarkan j enis bahannya. Hal ini agar lebih memudahkan pada tahap selanj ut nya. Sehingga hasil, yang diperoleh memiliki densit as yang sama.

Pencucian 
Pencucian ini berfungsi agar dapat menghilangkan kot oran- kot oran pada j aring, maupun menghilangkan aroma tak sedap pada j aring.

Pengeringan

Set elah dilakukan proses pencucian, kemudian tahap pengeringan. Pengeringan ini bisa dilakukan dengan bant uan mat ahari.

Pengaplikasian

Set elah tahap pengeringan, j aring sudah bisa diaplikasikan sebagai pengganti busa dan dakron sesuai kebut uhan.

\section{Kesimpulan}

Limbah j aring ikan memiliki pot ensi sebagai pengganti busa maupun dakron dalamskala indust ri rumah tangga. Hal ini dikarenakan sif at nya yang tidak mudah hancur dan dapat memenuhi ruang sesuai dari bent uk wadahnya.Sehingga masalah pembuangan limbah j aring disekit ar area pencarian ikan dapat terat asi.

Unt uk menj adikan gagasan ini dapat terlaksana diperlukan adanya kerj asama dan kesadaran masyarakat akan pent ingnya menj aga lingkungan sekit ar, terut ama dengan cara mendaur ulang barang yang sudah tidak terpakai menj adi barang pakai.

\section{Daftar Pustaka}

Clarest a, G. (2015). Adidas Buat Sepatu dari Jaring dan Sampah Laut. - : Inilahcom

M R. D., Sugito, R., \& At maj a, T. H (2018). Sampah Anorganik sebagai Ancaman di Kawasan Ekosist emHut an Manggrove Kuala Langsa. Jurnal Jeumpa , 5(2), 84-90.

Mainnah, M, Diniah, \& Iskandar, B. H (2016). Perpaduan Serat Daun Nanas (Ananas Comosus) dan Kit osan sebagai Mat erial Alat penagkapan Ikan Ramah Lingkungan. Marine Fisheries, 7(2), 149-159.

Marzuki, R. D., Sugit o, R., \& Atmaj a, T. H (2018). Sampah Anorganik sebagai Ancaman di Kawasan EkosistemHut an Manggrove Kuala Langsa. Jurnal Jeumpa , 5(2), 84-90.

Sahwan, F. L., Martono, D. H, Wăhyono, S., \& Wisoyodharm, L A (2005). Sistem 
Pengelolaan Limbah Plast ik di Indonesia. Jurnal Teknik Lingkungan , 6(1), 311- 318.

Suswant o, J . (2019). FI VB Kampanyekan Daur Ulang Jaring I kan Bekas unt uk Net Voli. J akarta: Ant araNews.com

Wulan, A. (2018). Koleksi Busana Premiumdari J aring Ikan dan Limbah Nilon. jakart a: Liput an 6. 